\title{
Collaboration of Child Protective Services and Early Childhood Educators: Enhancing the Well-Being of Children in Need
}

\author{
${\text { Karmen } \text { Toros }^{1} \text { (D) Keidy Tart }}^{1} \cdot$ Asgeir Falch-Eriksen ${ }^{2}$ \\ Accepted: 23 December 2020 / Published online: 9 January 2021 \\ (c) The Author(s), under exclusive licence to Springer Nature B.V. part of Springer Nature 2021
}

\begin{abstract}
This paper examines the role of interprofessional collaboration in the identification and reporting of a child in need. Such collaboration is especially important in the context of the global pandemic caused by the novel Coronavirus disease of 2019, known as COVID-19. The child protection system must have the capacity and resources to respond to increased demands during this time, and early childhood educators serve as an essential link for child protective services in identifying and reporting a child in need. As an effective system to accomplish these two aims requires a working collaboration among its participants, Bronstein's interdisciplinary collaboration model was used as a framework to interpret this practice. A small-scale qualitative study was conducted that included principals of nursery schools and child protection workers from one region in Estonia. Findings indicate that effective collaboration was believed to require communication and ongoing systematic relationship building. Collaboration in practice varied, as principals reported a high turnover rate for the child protection workers, which hindered the development of a working relationship and support for the process of noticing and thereby identifying a child in need. In contrast, child protection workers assessed collaboration more positively, recognizing the need to have a supportive system in place for nursery schools. Both groups of collaborators acknowledged the need to train teachers, particularly to conduct joint training exercises to foster a common understanding of the child in need and of the intervention process itself.
\end{abstract}

Keywords Interdisciplinary collaboration $\cdot$ Child protection services $\cdot$ Nursery school $\cdot$ Child in need $\cdot$ Early childhood educator

\section{Introduction}

Children's well-being, or lack of it, sets the path for their further development, which makes it imperative to identify, at an early age, those children who are in need of support services (Green et al. 2018, 2020; Kovan et al. 2014; McKee and Dillenburger 2012; Pölkki and Vornanen 2016; Treacy and Nohilly 2020). As Bartlett and Smith (2019) discussed, vulnerabilities caused by various traumas during

Karmen Toros

lai@tlu.ee; karmen.lai@tlu.ee

Keidy Tart

keidy.tart@tlu.ee

Asgeir Falch-Eriksen

asgeir.falch-eriksen@nova.hioa.no

1 Tallinn University, Narva mnt 25, 10120 Tallinn, Estonia

2 Oslo Metropolitan University, Stensberggaten 26, 0170 Oslo, Norway the child's first years are widespread. Similarly, Farrell and Walsh (2010) indicated the seriousness of child neglect and abuse in the context of early childhood. In Estonia, the number of children without parental care and in need of assistance is increasing: in 2005, 30 children were registered; in 2011, this number increased to 95 children; and in 2015, it increased again to 122 children (Statistics Estonia 2020). Children who do not receive the services they need face a greater threat to their well-being due to the lack of assistance and assessment of an appropriate intervention.

According to the UN Convention on the Rights of the Child (UNCRC 1989) and Article 19, which stipulates a child's right to protection from violence, each signatory to the convention must establish a system of reporting and referrals (Falch-Eriksen 2018). The success of any Child Protection Service (CPS), irrespective of country, is dependent upon being informed of detriments that children are subjected to, or else such a service would not work. Said differently, if a right to protection is to be enforced at all, a system of reporting must work effectively across the different arenas 
in which children can be observed. Different types of health care and social services, school nurses, kindergartens, and the educational system all need to be engaged in enforcing each child's right to protection. Collaboration across sectors is thereby a precondition for meeting international obligations.

In the context of child welfare and protection, early childhood educators have a crucial role in identifying and reporting a child in need as a matter of enforcing a child's right to protection. To promote a child's development and well-being, collaboration between early childhood educators and CPS becomes key (Albuquerque et al. 2020; Klein and Jekielek 2018). Early childhood educators see children daily and notice not only physical symptoms but also behavioural changes acquired through prevailing bad care (Farrell and Walsh 2010; Feng et al. 2009). Given the role of early childhood educators, they become an essential link for the CPS to the child, and for ensuring that the child receives the support and assistance needed. Research has shown that "the identification and reporting of suspected abuse to be critical steps in helping children in need" (Feng et al. 2009, p. 405) but it corresponds also to the educational systems role in enforcing the rights of the child, and that any infringements upon such rights must be reported to the proper agency, which, in this case, is the CPS. Also, and most importantly, it can be argued that early childhood educators in a nursery school stand first in line to observe children in need.

Benbenishty and Fluke (2021, p. 24) argued that "decisions in child welfare are highly uncertain, even with vocational education". Early childhood educators are in a more complex position because their vocational education does not focus on child protection matters. This presents a challenge, as this occupational group is equally responsible for securing the rights of the child. Therefore, this study explored early childhood educators' and child protection workers' perceptions and experiences of collaboration for identifying and reporting a child in need in one region in Estonia, and specifically the factors facilitating or prohibiting collaboration. Such views are important to gather because participants' perceptions of the advantages of a collaboration allow for a better understanding of the potential of such a relationship (Albuquerque et al. 2020). Although the paper has a narrow empirical data sample and also applies qualitative methodology, the findings and discussions in this exploratory study make claims about how CPS practices are designed that are highly relevant in CPS contexts across nation-states. Estonian legislation is modern and aligned with CRC demands, and policy development and public discourses revolve around rights-based practices that are sought and implemented around the world.

Collaboration, in the sense of early childhood educators identifying and reporting a child in need, is especially significant during the time of a global pandemic, as consequences of coronavirus disease (COVID-19) might have far-reaching implications for children in early childhood (Toros and Falch-Eriksen 2020). The crises that the pandemic impose leads to changes in the care of children through changes in their psychosocial environment (Witt et al. 2020), and the crises as such pose serious additional risks to children who already faced an increased vulnerability to their physical and emotional well-being (Ager et al. 2010). Children face increased vulnerabilities and higher risks not just due to the virus itself but also the societal consequences of the pandemic, as the environments in which children grow and develop are disrupted. Families, communities, and daily routines normally promote resilience in children towards challenging situations (Dalton et al. 2020), but the wide disruptions to these support structures can negatively impact children's well-being, development and protection (Alliance for Child Protection in Humanitarian Action 2020). Although the study presented in this paper was conducted prior to the COVID-19 pandemic, the collaboration between early childhood educators and child protection workers might be more relevant than ever in this context.

\section{Facilitating the Right to Protection for the Child in Need}

Child protection work is challenging by nature because it includes complex decisions (Benbenishty et al. 2015). Variables include the many, many parties to consider, care contexts that are hard to map, legal restrictions, the ongoing controversy of intrusion and the called-upon need to infringe upon the fundamental right to family life, and strict demands towards each decision being in the best interests of the child. CPS practice is considered an age-old public responsibility, and one that is difficult to enforce (Duncan 2019; Hultman et al. 2018). Also, decision-making often involves limited knowledge and carries uncertainty in the interpretation of the care context, and whether or not to do something (Whittaker 2018). Early childhood educators, therefore, are crucial partners for CPS, as CPS is dependent upon information about children in need of help. Without early childhood educators sharing relevant information, and conducting referrals, the CPS becomes blind. To expand on this metaphor, the CPS needs eyes and ears to locate children in need of protection, and for those eyes and ears to report cases of failed care and children in need.

According to the Estonian Child Protection Act (2014, $\S 26$ ), the child in need of assistance is defined as:

A child whose well-being is threatened or in the case of whom doubt has arisen concerning his or her abuse, neglect or any other situation violating the rights of the 
child and a child whose behaviour threatens his or her well-being or the well-being of other persons.

This provision aligns with the CRC and the need for any public officials to have the general duty to secure and enforce the right of the child to protection from violence. Therefore, any public organisation within local government, as well as CPS and its child protection workers, have a particular role of securing the rights of children in need and providing protection and assistance, whenever needed. To assist children in need and make decisions contributing to the best interest of the child, child protection workers within the CPS need effective collaboration. Early childhood education teachers are in an especially important position with regard to unravelling the lack of care or detriments to children (Scannapieco et al. 2019). These professionals spend a considerable amount of time with children daily and, therefore, they are one of the most important contacts for a child in need. Through professional training, they can unravel situations if something is not right with the child in their practices, including finding out if the child is physically harmed or if the child behaves increasingly different from what can be deemed normal or expected from the child. Bell and Singh (2017) and Hood et al. (2017) indicated that the probability of an educator recognising abuse or neglect is high.

Concerning the responsibilities of professionals working with children, the Estonian Child Protection Act (2014, §9) stipulates a broad and general mandate to any public organisation to contribute to enforcing the child's right to protection through the following:

State and local government agencies and the officials thereof, legal persons in public and private law shall ensure the notification of the public of child protection measures, paying special attention to the disclosure of information necessary for assisting children in need or in danger.

In the context of this paper, it clearly stipulates that early childhood education teachers have a responsibility when it comes to enforcing the rights of the child and the right to protection by securing effective collaboration with child protection workers in reporting the child in need. This institutional setup of providing a general mandate to any public official working with children to enforce the rights of the child, it can be argued, is derived from the CRC, and it is also a demand presented to any nation-state claiming to abide by and enforce the CRC.

Nevertheless, identifying and reporting a child in need is not a straightforward process, but it is a matter of professional practice. This means having the ability to identify challenges to the child's care context, knowing what the challenges imply, and, finally, determining what to do about them (Falch-Eriksen 2018; Molander 2016). Only then can each child's right to protection be predictably enforced (Farrell and Walsh 2010). Hence, the mandatory reporting of child maltreatment is a complex, yet essential, responsibility tasked to many professional groups working with children (Ayling et al. 2020; Scannapieco et al. 2019).

\section{Collaboration as a Key to Enforcing the Right to Protection}

The idea that CPS-practices can be effective without consolidating all of the arenas in which children participate into an integrated system of reporting is implausible. Therefore, any CPS across any nation-state depends upon collaboration to work. This became even more clear during the COVID19 pandemic, as the regular system of reporting shut down (Toros and Falch-Eriksen 2020).

Looking at some of the classic contributions with regard to professional collaboration, it can be seen that collaboration involves groups of people joined together with the same goals (Appley and Winder 1977). Stafford et al. (1984, p. 4) described collaboration "as an intensive, planned process resulting in a productive meeting of agencies on a point of mutual concern and commitment to reach mutually positive results". Also, whenever different public organisations are mandated to reach the same aim, which in today's case has a lot to do with rights, Bruner (1991) discussed collaboration among various institutions in the context of promoting children's well-being not only for using resources effectively, but also to avoid duplication.

Different public organisations' collaborative practices with the CPS - which, on the one hand, involve the identification of a child in need, reporting and providing assistance to the CPS, and, on the other, moving together towards the common goal of securing the rights of the child -require similar understandings of what the aim is, as well as what the roles are among all collaborative parties (Konrad 2020; Phillips and Walsh 2019). Then, as collaboration not only cuts across public organisations but also academic disciplines and professional backgrounds, and thereby becomes interdisciplinary, a coordinated effort to enforce rights in the face of complex social challenges becomes even more important (Hutchinson and Korazim-Körösy 2017; Konrad 2020; Scannapieco et al. 2019).

Bronstein (2003) developed a model for guiding interdisciplinary work, one which is especially relevant to social work (not only among social work professionals, but the part of other professions that can be deemed as social work), as effective collaboration requires knowledge of what constitutes collaboration. The current paper uses this model as a framework to interpret the collaboration of CPS (child protection workers) and early childhood education (principals of nursery schools). 
Bronstein's (2003) interdisciplinary collaboration model-based on a multidisciplinary theory of collaboration, service integration, role theory and ecological systems theory-incorporates five components that create interdisciplinary collaboration between child protection workers and other specialists (see Table 1).

In the context of the study presented in this paper, interdependence translates into the child protection worker and early childhood educator clearly comprehending each other's roles in promoting a child's well-being by enforcing that child's right to protection and acting according to their roles. To support and provide assistance to the child in need, the child protection worker requires input from the educator in terms of identifying and reporting suspected abuse or neglect. Here, knowing what to do, what to search for and the clarity of one's role is imperative for the educator to contribute to identifying and reporting in a professionally coherent manner. The collaborative effort, then, stipulates that the CPS require information to assist the child in need, while teachers requires the skills to identify children in need, and knowledge regarding how to report. Newly created professional activities can be seen in reforms, which create new organisational designs. Examples include knowledge enhancement training, during which child protection workers strengthen educators' skills and knowledge of what to notice in children in the child's care context, or joint systematic roundtables, where discussions explore how to tackle the challenges related to children's well-being. As Lalayants et al. (2011) stated, each abusive and neglectful situation is a unique phenomenon and, therefore, not always easily detected. This is why flexibility is a crucial component of collaboration - both child protection workers and educators require adaptability to respond, and serve as inputs in recognising a child in need. In terms of collective ownership of goals, a child is entitled to special care and assistance, and every child has the right for protection (UNCRC 1989), which also applies to the early childhood education setting. To act in the best interest of the child, the ultimate goal of education and the CPS is to support the child to grow into a competent and functioning human being, and to strengthen the child's well-being and ability to cope effectively as an adult. Collaborative practices must therefore commit to this common goal — the right of the child to well-being — and act respectively within their profession. The last component of the model, reflection on the process, indicates child protection workers and educators must think and talk about their working relationship and process, including how to improve this relationship. Participants' perceptions of collaboration enable us to understand the collaboration between actors and the challenges that must be addressed to facilitate more efficient collaboration, in order to achieve the desired goal of the well-being of children (Albuquerque et al. 2020).

\section{Study}

This qualitative study was undertaken to explore early childhood educators' and child protection workers' perceptions and experiences of collaboration for identifying and reporting a child in need with a focus on factors facilitating and hindering their collaboration. This study was reviewed and approved for human subjects by a committee of scholars at the first and second author's university.

\section{Participants}

The study was conducted among child protection workers employed by local governments and principals of nursery schools in one region of Estonia. Principals were invited to participate because they have the role of communicating between the nursery school and other specialists. All ten nursery school principals in the region were approached to

Table 1 Bronstein's (2003) interdisciplinary collaboration model in the context of collaboration between the child protection worker (CPW) and early childhood educator (ECE)

\begin{tabular}{|c|c|c|}
\hline \multicolumn{2}{|l|}{ Interdisciplinary collaboration } & \multirow[t]{2}{*}{ Collaboration between the CPW and ECE } \\
\hline Component & Description & \\
\hline Interdependence & $\begin{array}{l}\text { Occurrence of and reliance on interactions among } \\
\text { professionals, including an understanding of } \\
\text { everyone's roles }\end{array}$ & $\begin{array}{l}\text { A clear comprehension of each other's roles and } \\
\text { acting according to their roles in enforcing the } \\
\text { child's right to protection }\end{array}$ \\
\hline Newly created professional activities & Collaborative acts, programmes and structures & $\begin{array}{l}\text { Reforms, which create new organisational designs } \\
\text { (e.g. training, roundtables) }\end{array}$ \\
\hline Flexibility & Deliberate occurrence of role-blurring & $\begin{array}{l}\text { Adaptability to respond and serve as inputs in } \\
\text { recognising a child in need }\end{array}$ \\
\hline Collective ownership of goals & $\begin{array}{l}\text { Shared responsibility of reaching goals, including } \\
\text { client-centred approach }\end{array}$ & $\begin{array}{l}\text { Provision of special care, assistance, and protection } \\
\text { by CPW and ECE }\end{array}$ \\
\hline Reflection on the process & $\begin{array}{l}\text { Attention to the process of working together, } \\
\text { including feedback }\end{array}$ & $\begin{array}{l}\text { Maintaining and improving working relationships } \\
\text { between CPW and ECE }\end{array}$ \\
\hline
\end{tabular}


participate in the study, of which five agreed. Reasons for refusal were related to high workload. Participants ranged in age from 23 to 41 years, and their working experience ranged from 2 to 15 years. The average number of children in the nursery schools was 108, ranging from 23 to 240 children. Regarding child protection workers, all five child protection workers in the region were invited to participate, and all of them agreed. Child protection workers' age ranged from 27 to 56 years, and their working experience ranged from 8 months to 10 years. The number of children living in local government care ranged from 550 to 1400 children, and the average number of active cases was 36 . The final sample consisted of five child protection workers and five principals of nursery schools. All respondents were women. There was no compensation for participation, and all respondents gave their informed consent to participate in the study.

\section{Interview Design and Data Collection}

Participants were contacted by phone to discuss their participation in the study. During the call, the researcher explained the aim of the study, interview process, confidentiality, and anonymity of information regarding records. After someone verbally agreed to participate, a time and place for an interview were set. The location for the interview was chosen by the participant-all participants chose to be interviewed in their offices in November 2019. The interview guide was developed before interviews were conducted and covered themes such as the perception of a child in need (child protection workers, principals), experiences of informing children in need (principals), reasons for not reporting the child in need (principals), expectations, evaluation on collaboration (child protection workers, principals), etc. For most questions, participants were asked to share examples of their experiences. The last part of the interview asked participants whether they would like to address any issues that were not covered in the interview, and what they thought was important to add, related to the topic discussed.

At the beginning of the interview, participants were informed that their participation in the research process was voluntary, they were not influenced to participate, and they were reminded they could terminate their agreement to participate at any stage without consequence. Participants were assured that the information shared during the interview would be kept anonymous. The interviews lasted an average of $64 \mathrm{~min}$. Each interview was tape recorded and later transcribed verbatim. After the transcription of the data, recorded files were deleted. The second author conducted all of the interviews.

\section{Data Analysis}

The actual process of transcription started immediately after the first interview. Thematic analysis of the findings was conducted using the principles outlined by Terry et al. (2017), which consist of generating initial codes before searching for, reviewing, refining and labelling themes. According to Clarke and Braun (2013), thematic analysis is suitable for enabling one to learn about people's experiences or understandings and the construction of phenomena in particular contexts. To enhance the reliability of the data analysis, the first and second authors conducted the data analysis-both authors conducted the initial analysis independently. Analysis of the data began with transcribing the material and reading the interviews multiple times to gain an overall understanding of the data, followed by generating initial codes from the data (open coding). Initial codes and themes were identified, which were then either supported and verified by further analysis or merged with corresponding themes and codes. As the number of participants was small, transcripts were manually coded using word processing software. The final themes and codes in the article were defined through the comparison of and discussion about the findings between the two authors. Consistency in the common labels and themes was achieved by reaching a consensus. Themes were then further shaped and clarified through revisiting the texts for defining and naming themes (see Table 2). To ensure confidentiality, identifying details of the participants, locations or identifying details of other individuals or agencies were edited during transcription. The audio files were deleted after transcription of the interviews.

The main themes are introduced in the following section, including quoted data extracts to illustrate the connections between the raw data and the conclusions drawn. As participants provided their responses in the Estonian language, data analysis was conducted in Estonian and translated afterwards into the English language while the manuscript was being written.

\section{Findings}

In terms of receiving information about a child in need, child protection workers assessed the nursery school as one of the main sources for reporting a child in need-the first being police, followed by school and then nursery school. Child protection workers emphasised that the number of children was increasing yearly, and that every week they had new registrations. Nursery school principals explained they generally receive their initial information about a child in need from teachers, followed by their own observations and parents. As one principal reflected, "As the nursery school is relatively small, I am in contact with all the children daily, 
Table 2 Reflections on collaboration regarding a child in need: two main themes and labels

Child protection workers' reflections

Children in need: who

Perception of a child in need: lack of family economic well-being (food, income); lack of parental care (physical, emotional); parental alcohol abuse; a child with special educational needs

Profile with a child in need in practice: truancy; special educational needs; behavioural disorders; abusive home environment; parental substance abuse

Collaboration: what and how

Meaning of collaboration: co-facilitation; shared responsibility; not overlapping: clarity in roles and tasks; bi-directional communication; continuous feedback

Collaboration in practice: work in progress; linear communication

Activities to strengthen collaboration: past and future needs: observation of children at the nursery school; networking system; training for educators; future: a comprehensive support system for nursery schools, focus on prevention work, joint training

Obstacles to collaboration: high expectations; non-reporting of a child in need; autocratic leadership

Principals' reflections

Child in need: who and how

Perception of a child in need: lack of well-being in general; a child with behavioural issues (aggressive child, emotional behavioural disorder); a child with special educational needs

Experience with a child in need in practice: behavioural issues

Provision of support: conversations with parents; specialists in the nursery school (speech therapist), specialists outside the nursery school (social pedagogue, child protection worker)

Collaboration: what and how

Meaning of collaboration: working towards common goals; joint planning

Collaboration in practice: irregular support; various child protection workers

Activities to strengthen collaboration: past and future needs: roundtables, information-sharing with parents, encouraging staff for collaboration with CPS; future: CPS-related initiatives: CPS monitoring on sight, informed knowledge of CPS roles

Obstacles to collaboration: lack of motivation from CPS; previous negative relationships with CPS

and therefore if there is something different in a child, it can be noticed' (H3).

\section{A Child in Need}

\section{Perception of a Child in Need}

Throughout the interviews, both groups of participants used the word 'well-being' related to the child in need-for example, a lack of well-being. In elaborating further, child protection workers discussed a lack of economic well-being and physical and emotional parental care, specifying a lack of care also due to parental alcohol abuse. Principals' perceptions of a child in need comprised a general lack of wellbeing, but this was merely related to the child's behavioural issues, such as an aggressive child or an emotional behavioural disorder. Children with special educational needs were mentioned by both groups of collaborators.

\section{Profile/Experience with a Child in Need in Practice}

When describing children in need reported in practice, child protection workers pointed to children with unapproved absences from school (truancy) as being the largest group, followed by children with special educational needs, behavioural issues, abusive parents and parental substance abuse. All principals had experiences with children in need in their nursery schools, primarily children with behavioural issues. According to them, children in need are increasing yearly. Principals reflected that over the last 10 years, a child in need was always reported to the local authority-teachers informed the principals of their suspicions of a child in need and then help was sought. As one principal explained, “... it is rather that we scream [contact child protection worker] too much, more than it is worth it. Rather immediately. We have an agreement with our staff that we ring the tocsin [alarm], we are not silent" (H5). Previously, children in need were not reported due to the principals' lack of knowledge and a lack of specialists within the nursery schools.

\section{Provision of Support}

Child protection workers' task in receiving a report is stipulated in the Estonian Child Protection Act $(2014$, §29), effective since January 2016:

The local government [child protection worker] shall, within ten days after becoming aware of a child in need 
of assistance, make a decision on whether or not to commence case management, start a case plan and the local government shall establish and document the opinion of the child.

Furthermore, the Child Protection Act specifies that a child's well-being must be assessed across physical, medical, psychological, emotional, social, cognitive, educational and economic domains. All interviewed child protection workers outlined their actions when receiving information about a child in need based on the Child Protection Act as mentioned.

Principals discussed their actions for providing support and enhancing the well-being of the child once they were informed about a suspected child in need. First, initial support was provided by the nursery school in collaboration with the principals and teachers-they have a conversation with the parents of the child and attempt to engage in a collaboration. All of the principals pointed out that, generally, collaboration with parents is difficult, if not impossible. Two nursery schools have specialists (speech therapists and social pedagogues) who are included in the teamwork, if necessary. If the nursery school lacks competency or the case is complex, the principals reach out for help outside the nursery school (social pedagogue, speech therapist and/or child protection worker).

\section{Collaboration}

\section{Meaning of Collaboration}

Child protection workers' interpretations of collaboration included 'doing together', meaning co-facilitating with each other's help rather than having the case handed over. The main idea was that a child cannot be helped by one person. As one child protection worker noted, "Child protection workers make the final decision about the intervention but in order to come to that decision, this work cannot be done by one person only" (CPW2). An important component of this is shared responsibility, meaning that both collaborators are aware of what is happening to the child, including interventions. At the same time, during this process, collaborators have their own tasks and should avoid overlapping or stressing the child within the process of assisting and supporting them. Therefore, clarity of collaborators' tasks and roles is crucial to ensuring that resources are used effectively. As emphasised by one child protection worker:

Everyone has to know, what can they do to support the child ... So that responsibility is shared. It cannot be that one takes the responsibility and is found guilty if the well-being of the child is not supported for some reason. (CPW1).
This requires bi-directional communication. Furthermore, feedback was discussed in terms of reflecting on the role of the nursery school related to the process of a case or what activities are chosen to best help the child.

For the principals, collaboration was an activity during which all parties give their best to achieve the aim to ensure that the child receives help. To achieve this, joint planning is important. The nursery schools' role in supporting a child in need was to implement the work on-site, as one principal explained:

We would be an extension, a helping hand in the nursery school. We would carry out the practice, CPS would teach us how to do it. They are competent in this field. We would both follow the same road, not that we act separately and use different approaches. (H5)

\section{Collaboration in Practice}

As mentioned, participants were asked to give examples throughout the interviews. From child protection workers' examples, collaboration, in general, was assessed as well the functioning of the relationship, especially in the case of previous positive collaboration experience. One worker explained, "Collaboration has been very good in the case of a prior positive working involvement. In that case, principals already know when and whom to contact and what are contributors' roles" (CPW4). Nevertheless, participants argued that improvements could make the collaboration more effective, primarily in the area of communication, which was thought to be rather linear.

Child protection workers considered themselves the main initiator of the collaboration by creating a network with a trusting environment so nursery school officials would be comfortable in asking CPS for help. In practice, child protection workers' examples indicated they were an active party (e.g., calling and writing emails). Notably, the workers emphasised communication as the basis for effective practice.

Principals, on the other hand, assessed collaboration with CPS as less positive - they described this relationship using words such 'satisfactory', 'collaboration varies', and 'depending', meaning help was not always provided. One of the principals described an example of her general practice with CPS, referring to the idea that effective collaboration requires building a relationship:

A child needs help, the family denies the situation of neglect. I informed CPS, as CPS should get involved in order to move on and help the child ... At some point, I followed up to learn whether someone is getting involved from CPS. In order to contact CPS, there is a general email/phone of the department, no specific person. The reason for this was that I did not get any 
reply from CPS ... I want to have a concrete person that I can contact if there is a child who needs help. I was told that there is no such person, all depends on the case. But I need one person to develop the working relationship with. (H4)

\section{Activities to Strengthen Collaboration: Past and Future Needs}

While discussing what has been done to develop collaboration and what needs to be done further, all five child protection workers acknowledged the past effort to be more related to schools, but this effort did not extend to nursery schools. Nevertheless, several activities were outlined with nursery schools as single actions. For example, one child protection worker started going to a nursery school to observe how children who have just started at the school have adapted, and whether they are exhibiting behavioural issues or social skill deficits. Another worker focused on creating a networking system to map specialists outside the nursery school, so that the principals can contact the most appropriate specialist according to the need. Training for nursery school educators was also mentioned. As the setting for this study is isolated from the main island, organising a specialist for such training is challenging. Previously, training was organised for the whole nursery school to understand the profile of children and families living in that region, and how to recognise children in need.

Principals discussed organising roundtables for parents, child protection workers, and other specialists involved in promoting the well-being of a child. Some examples of practical activities specifically addressing how to communicate with parents and give them advice on supporting the child in the family (behavioural issues) were mentioned. Furthermore, some of the principals document suspicions and other observations. One of the principals encourages her staff to report a child in need and collaborate with relevant specialists. Her standpoint was to be a supportive leader:

I am the head here, and my role is to encourage teachers to help and support the child. My role is to contact CPS and inform them about the situation. This is not the task of the teacher, but mine. I must listen and notice. (H3)

Participants shared thoughts on what is needed to strengthen the collaboration. Child protection workers see the importance of building a comprehensive support system for nursery schools, meaning a social pedagogue, speech therapist and psychologist should be part of the network. In Estonia, not all nursery schools have permanent specialists on-site, which means the school must call in a specific specialist depending on the situation. Efficient collaboration translates to a family getting help in a timely manner before the situation becomes worse. Furthermore, prevention work was mentioned, particularly in terms of behavioural issues, including the need for training:

We need to think together, as there are more and more children with complicated behavioural issues; so we must think early how to prevent, to be one step ahead, what should be done in such cases. We need to know if a certain situation happens, we know what to do and whom to turn to for help. This can be achieved by joint training, think tanks, planning activities and such. (CPW3)

Principals reflected on building a relationship with the child protection worker throughout the interviews, including discussing and establishing the issues with which they felt CPS could help. Principals were worried they did not know when to contact CPS and that because of this, the child might not get the help they need. Three principals stated it would be useful if the child protection worker regularly attended the nursery school to observe children, not only when they were invited or needed; in addition, face-to-face contact was noted as more effective when compared with telecommunication. One of the principals emphasised that it was important to know the role of the child protection worker and their willingness to help as well as the possible interventions and the influence of these actions on the child in need.

\section{Obstacles to Collaboration}

Some obstacles to collaboration were discussed. Child protection workers' main concern was high expectations from principals, which may complicate their working relationship and further collaboration. According to the workers, principals want fast solutions, even though cases of children in need are complex and require in-depth assessment. Furthermore, non-reporting and autocratic leaders were highlighted as issues - the leader may lack knowledge of when to report or attempt to solve cases themselves. In these cases, CPS obtains information about the child in need late, which means the child is left suffering and may not get the help needed. Principals described worrying about child protection workers' motivation to find and work towards solutions. Previous negative relationships were also identified as an obstacle. However, one of the principals emphasised that no obstacles existed with CPS, only with the families of children in need. 


\section{Concluding Thoughts}

Lalayants et al. (2011, p. 156) stated that "collaboration among CPS and other disciplines has been increasing based on the realisation that no one discipline alone can understand and handle such a complex problem as child maltreatment". Today, this is a continuously important theme not only regarding facilitating collaboration for increasing the well-being of a child but also due to the outbreak of the COVID-19 global pandemic, which poses significant risks to children's well-being and developmental progress, especially for children in need (Toros and Falch-Eriksen 2020). In the face of this pandemic, the CPS system must have the capacity and resources to respond to an increased need for support and minimise the effects on vulnerable populations (Sistovaris et al. 2020). A global pandemic crisis poses increased vulnerabilities and higher risks to children who are typically in need of the protective measures of CPS (Toros and Falch-Eriksen 2020). These are challenging times for everyone, especially for vulnerable families and children (Kelly and Hansel 2020; Usher et al. 2020).

A crisis can lead to children being subjected to a type of detriment that in regular times could have been avoided. In the context of child welfare and protection, child protection workers have the key role of supporting children in need, but they are highly dependent on collaborators who work with children daily and, therefore, have valuable insight into the potential children in need. Early childhood educators and nursery schools are critical links to CPS for identifying and reporting children in need; however, an effective system for identifying and reporting requires a working collaboration.

Bronstein (2012) argued that even when professionals recognise the value of interdisciplinary collaboration, the process is complex and challenging. For example, Howarth and Morrison (2007) found that interdisciplinary collaboration may cause tension and disagreements because specialists in different spheres understand the 'child in need' variously, and this variation can have an impact on services reaching the child. Lalayants and Epstein (2005) referred to challenges in the division of roles and (unexpected) expectations related to collaboration. In the current study, child protection workers' and nursery school principals' understanding of collaboration coincided with Bronstein's (2003) interdisciplinary collaboration model, as participants discussed the knowledge of collaborators' roles and tasks, shared responsibility working towards enhancing the wellbeing of children (in need) and joint activities and planning. Both groups of collaborators have implemented activities to establish more efficient collaboration, with an emphasis on building a working relationship. Communication and ongoing systematic collaboration were considered the basis for collaboration. Perceptions of a child in need variedchild protection workers' views were more comprehensive compared with those of principals, who focused mainly on behavioural issues in their reflections, whereas child protection workers also emphasised communication, feedback, and clarity of the roles. This may be a serious challenge, as well-being is a broader concept and other domains of wellbeing can be undetected, meaning a child in need may be left without support in the early stages of abuse or neglect.

Reflections from practice indicated that even though CPS has the role of organising child protection in the area, including the assessment of children in need and to decide interventions, principals assumed partial roles of CPS by initiating the process of unofficial assessment with parents and involving CPS in the case of unsuccessful engagement.

Bell and Singh (2017) argued that educators are not responsible for investigating and determining whether maltreatment occurred, but they are responsible for reporting any reasonable suspicion. One of the reasons for principals assuming the task of inquiring about the case might be dissatisfaction with the lack of motivation and experiences of not receiving needed help from CPS in the past. Also, the high turnover rate among child protection workers hindered the development of a working relationship and, furthermore, support for the process of noticing or identifying the child in need. Nonetheless, child protection workers assessed collaboration more positively, recognizing the need for a more comprehensive supportive system in nursery schools, including specialists working on-site (e.g., social worker, psychologist).

As mentioned, communication matters; this includes transparency of the roles and a clear vision of tasks within the competencies to avoid duplication and possible harm to the assessment procedure, as this requires specific approaches and methods with children and their parents to encourage building a trusting relationship to enable support and assistance. Lehman Held et al. (2019) found that strong communication and collaboration skills were consistently imperative for developing a strong working relationship. Furthermore, trust was considered important for interprofessional collaboration in the context of creating a collaborative environment. Villagrana (2020) elaborated that in trusting relationships collaborators are more likely to initiate collaborations. Therefore, going back to the roots is crucialinvesting time in working relationships with collaborators.

In the context of the COVID-19 pandemic lockdown, Bérubé et al. (2020) argued that supportive systems, including healthcare and CPS, could not meet the needs of children due to the closing of schools and childcare centres. Several studies (Toros and Falch-Eriksen 2020; Jentsch and Schnock 2020) found that one of the challenges of COVID-19 for CPS was the loss of collaboration 
opportunities with key partners, including nursery schools. Jentsch and Schnock (2020) reported that the lockdown did not support the reporting process. Similarly, Turner (2020) addressed limited collaboration from key partners due to COVID-19. Child protection workers in Toros and FalchEriksen (2020) study stated a decrease in referrals from the collaboration partners, which was believed to be partly due to the collaboration partners' perception of an overload of work in CPS during the pandemic. Collaboration partners, including (nursery) schools, play an important role in contributing to the child-in-need reporting system in daily practice and in crisis settings. In this context, the need for effective collaboration and a clear understanding of collaboration partners' roles is even greater.

\section{Limitations and Implications}

These findings are drawn from a small, qualitative study conducted with a limited number of specialists in one region of one country and, therefore, findings may not be generalisable. Additional research with larger samples, including a quantitative study, will provide the opportunity to explore responses in greater depth. However, this study is a test case that reinforces the well-established claim of the importance of collaboration between CPS and early childhood educators for identifying children in need at early stages of abuse or neglect. None of the professionals involved must wait for other parties to initiate the collaboration; rather they can take an active role in building a working relationship for effective collaboration. An ongoing interdisciplinary collaboration should be standard in these professions; therefore, a more systematic approach is needed for professionalising both CPS workers and early childhood educators, as well as other specialists working with children throughout their studies. Both collaborators in the current study found that strengthening collaboration requires training - training of teachers to identify the child in need, but also joint training for a common understanding of the child in need and the helping process. Hood et al. (2017) emphasised that as multiple thresholds coexist, it is therefore crucial for the education to incorporate various aspects of interprofessional collaboration. Collaborative learning opportunities during professional education, including practice learning through field placement, would allow educators to teach and supervise in practise collaboration, and provide knowledge and skills concerning how to navigate the process of interdisciplinary collaboration. Moreover, Villagrana (2020, p. 98) proposed that CPS create guidelines for partners, including early childhood educators, to help to make collaborative decisions and share information. The strength of enhancing the well-being of children lies in the strength of professionals' ability and competence to work together to secure the protection of children in need.

Acknowledgements Special thanks to Teddy inspiring to conduct research on the promotion of the well-being of children.

Funding This paper was funded by the Estonian Research Council Grant (PSG305).

\section{Compliance with Ethical Standards}

Conflict of interest The authors declare that they have no conflict of interest.

\section{References}

Ager, A., Stark, L., Akesson, B., \& Boothby, N. (2010). Defining best practice in care and protection of children in crisis-affected settings: A Delphi study. Child Development, 81(4), 1271-1286.

Albuquerque, J., Aguiar, C., \& Magalhães, E. (2020). The collaboration between early childhood intervention and child protection systems: The perspectives of professionals. Children and Youth Services Review, 111, 104873.

Alliance for Child Protection in Humanitarian Action. (2020). Technical note: Protection of children during the coronavirus pandemic. Retrieved May 15, 2020, from https://alliancecpha.org/en/COVD1 9.

Appley, D. G., \& Winder, A. E. (1977). An evolving definition of collaboration and some implications for the world of work. The Journal of Applied Behavioral Science, 13, 279-291.

Ayling, N. J., Walsh, K., \& Williams, K. E. (2020). Factors influencing early childhood education and care educators' reporting of child abuse and neglect. Australasian Journal of Early Childhood, 45(1), 95-108.

Bartlett, J. D., \& Smith, S. (2019). The role of early care and education in addressing early childhood trauma. American Journal of Community Psychology, 64, 359-372.

Bell, M. M., \& Singh, M. I. (2017). Implementing a collaborative support model for educators reporting child maltreatment. Children \& Schools, 39(1), 7-14.

Benbenishty, R., \& Fluke, J. D. (2021). Frameworks and models in decision-making and judgement in child welfare and protection. In J. D. Fluke, M. López, R. Benbenishty, E. J. Knorth, \& D. J. Baumann (Eds.), Decision-making and judgement in child welfare and protection: Theory, research, and practice (pp. 3-26). New York: Oxford University Press.

Benbenishty, R., Davidson-Arad, B., López, M., Devaney, J., Spratt, T., Koopmans, C., et al. (2015). Decision making in child protection: An international comparative study on maltreatment substantiation, risk assessment and interventions recommendations, and the role of professionals' child welfare attitudes. Child Abuse \& Neglect, 49, 63-75.

Bérubé, A., Clément, M. -É., Lafantasie, V., LeBlanc, A., Baron, M., Picher, G., et al. (2020). How societal responses to COVID-19 could contribute to child neglect. Child Abuse \& Neglect. https:// doi.org/10.1016/j.chiabu.2020.104761.

Bronstein, L. R. (2003). A model for interdisciplinary collaboration. Social Work, 48(3), 297-306.

Bronstein, L. R., Anderson, E., Terwilliger, S. H., \& Sager, K. (2012). Evaluating a model of school-based health and social services: An 
interdisciplinary community-university collaboration. Children \& School, 34(3), 155-165.

Bruner, C. (1991). Thinking collaboration: Ten questions and answers to help policy makers improve children's services. Retrieved July 26, 2020, from https://files.eric.ed.gov/fulltext/ED338984.pdf

Child Protection Act. (2014). RT I, 06.12.2014, 1. Retrieved August 2, 2020, from https://www.riigiteataja.ee/akt/LasteKS.

Clarke, V., \& Braun, V. (2013). Teaching thematic analysis: Overcoming challenges and developing strategies for effective learning. The Psychologist, 26(2), 120-123.

Dalton, L., Rapa, E., \& Stein, A. (2020). Protecting the psychological health of children through effective communication about COVID19. The Lancet Child \& Adolescent Health, 4(5), 346-347.

Duncan, M. (2019). Children's experiences of statutory child protection interventions. In M. Duncan (Ed.), Participation in child protection. Theorizing children's perspectives (pp. 13-42). Cham: Springer Nature Switzerland AG.

Falch-Eriksen, A. (2018). Rights and professional practice: How to understand their interconnection. In A. Falch-Eriksen, \& E. Backe-Hansen (Eds.), Rights and professional practice: How to understand their interconnection (pp. 39-58). Cham: Palgrave Macmillan.

Farrell, A., \& Walsh, K. (2010). Working together for Toby: Early childhood student teachers engaging in collaborative problembased learning around child abuse and neglect. Australasian Journal of Early Childhood, 35(4), 53-62.

Feng, J.-Y., Chen, S.-J., Wilk, N. C., Yang, W.-P., \& Fetzer, S. (2009). Kindergarten teachers' experience of reporting child abuse in Taiwan: Dancing on the edge. Children and Youth Services Review, 31, 405-409.

Green, M. J., Tzoumakis, S., Laurens, K. R., Dean, K., Kariuki, M., Harris, F., et al. (2018). Latent profiles of early developmental vulnerabilities in a New South Wales child population at age 5 years. Australian \& New Zealand Journal of Psychiatry, 52(6), $530-541$.

Green, M. J., Hindmarsh, G., Kariuki, M., Laurens, K. R., Neil, A. L., Katz, I., et al. (2020). Mental disorders in children known to child protection services during early childhood. The Medical Journal of Australia, 212(1), 22-28.

Hood, R., Price, J., Sartori, D., Maisey, D., Johnson, J., \& Clark, Z. (2017). Collaborating across the threshold: The development of interprofessional expertise in child safeguarding. Journal of Interprofessional Care, 31(6), 705-713.

Howarth, J., \& Morrison, T. (2007). Developing multi-agency partnerships to serve vulnerable children and their families. Child Abuse and Neglect, 31(1), 55-69.

Hultman, E., Forkby, T., \& Höjer, S. (2018). Professionalised, hybrid, and layperson models in Nordic child protection-actors in decision-making in out of home placements. Nordic Social Work Research. https://doi.org/10.1080/2156857X.2018.1538897.

Hutchinson, G. S., \& Korazim-Körösy, Y. (2017). Do national welfare systems have an influence on interdisciplinary collaborations within schools of social work and their communities? The case of the Nordic countries. International Social Work, 60(1), 45-60.

Jentsch, B., \& Schnock, B. (2020). Child welfare in the midst of the coronavirus pandemic — emerging evidence from Germany. Child Abuse \& Neglect. https://doi.org/10.1016/j.chiabu.2020.104716.

Kelly, J., \& Hansel, K. (2020). Coronavirus: What child welfare systems need to think about. The Chronicle of Social Change. Retrieved May 20, 2020, from https://chronicleofsocialchange. org/child-welfare-2/coronavirus-what-child-welfare-systemsneed-to-think-about/41220.

Klein, S., \& Jekielek, S. M. (2018). Building effective child welfare. Early care \& education inter-agency partnerships: Lessons from research. Child Welfare, 96(4), 111-128.
Konrad, S. C. (2020). Interprofessional collaborative practice. Encyclopedia of social work online. New York: Oxford University Press.

Kovan, N., Mishra, S., Susman-Stillman, A., Piescher, K. N., \& LaLiberte, T. (2014). Differences in the early care and education needs of young children involved in child protection. Children and Youth Services Review, 46, 139-145.

Lehman Held, M., Black, D. R., Chaffin, K. M., Mallory, K. C., Diehl, A. M., \& Cummings, S. (2019). Training the future workforce: Social workers in integrated health care settings. Journal of Social Work Education, 55(1), 50-63.

Lalayants, M., \& Epstein, I. (2005). Evaluating multidisciplinary child abuse and neglect teams: A research agenda. Child Welfare, 84(4), 433-458.

Lalayants, M., Epstein, I., \& Adamy, D. (2011). Multidisciplinary consultation in child protection: A clinical data-mining evaluation. International Journal of Social Welfare, 20, 156-166.

McKee, B. E., \& Dillenburger, K. (2012). Effectiveness of child protection training for pre-service early childhood educators. International Journal of Educational Research, 53, 348-359

Molander, A. (2016). Discretion in the welfare state: Social rights and professional judgment. Abingdon: Routledge.

Phillips, J. D., \& Walsh, M. A. (2019). Teaming up in child welfare: The perspective of guardians ad litem on the components of interprofessional collaboration. Children and Youth Services Review, 96, 17-26.

Pölkki, P. L., \& Vornanen, R. H. (2016). Role and success of Finnish early childhood education and care in supporting child welfare clients: Perspectives from parents and professionals. Early Childhood Education Journal, 44, 581-594.

Scannapieco, M., Connell-Carrick, K., \& Casolaro, T. (2019). Psychosocial assessment of alleged victims of child maltreatment. In A. Giardino, M. Lyn, \& E. Giardino (Eds.), A practical guide to the evaluation of child physical abuse and neglect (pp. 469-491). Cham: Springer.

Sistovaris, M., Fallon, B., Miller, S., Birken, C., Denburg, A., Jenkins, J., et al. (2020). Fact sheet: Child welfare and pandemics. Policy Bench, Fraser Mustard Institute for Human Development, University of Toronto. Retrieved July 20, 2020, from https://cwrp. $\mathrm{ca} /$ publications/child-welfare-and-pandemics-information-sheet.

Stafford, B. G., Camp, J. C., \& Meer, P. V. (1984). The care linkages project. Nashville: Tennessee Children's Services Commission. Retrieved July 26, 2020, from http://malcat.uum.edu.my/kip/ Record/uum.b14943323/Description.

Statistics Estonia. (2020). Children without parental care and in need of assistance registered during the year. Retrieved August 5, 2020, from http://pub.stat.ee/px-web.2001/Database/Sotsiaalelu/datab asetree.asp.

Terry, G., Hayfield, N., Clarke, V., \& Braun, V. (2017). Thematic analysis. In C. Willig, \& W. S. Rogers (Eds.), The sage handbook of qualitative research in psychology (pp. 77-36). London: SAGE Publications Ltd.

Toros, K., \& Falch-Eriksen, A. (2020). A child's right to protection during the COVID-19 crisis: An exploratory study of the child protective services of Estonia. Children and Youth Services Review, 119, 105568.

Treacy, M., \& Nohilly, M. (2020). Teacher education and child protection: Complying with requirements or putting children first? Children and Youth Services Review, 113, 105009.

Turner, A. (2020). Most social workers say Covid-19 has negatively hit their work and the lives of those they support. Community Care. Retrieved December 1, 2020, from https://www.communityc are.co.uk/2020/05/28/social-workers-say-coronavirus-negatively -affected-services-people-they-support.

UNCRC. (1989). United nations convention of the rights of the child. New York: United Nations. 
Usher, K., Bhullar, N., Durkin, J., Gyamfi, N., \& Jackson, D. (2020). Family violence and COVID-19: Increased vulnerability and reduced options for support. International Journal of Mental Health Nursing. https://doi.org/10.1111/inm.12735.

Villagrana, K. M. (2020). A model to improve educational stability collaborations between child welfare and educational agencies: Applying the theory of collaborative advantage. Child Welfare, 98(2), 85-102.

Whittaker, A. (2018). How do child-protection practitioners make decisions in real-life situations? Lessons from the psychology of decision making. British Journal of Social Work, 48, 1967-1984.
Witt, A., Ordóñez, A., Martin, A., Vitiello, B., \& Fegert, J. M. (2020). Child and adolescent mental health service provision and research during the Covid-19 pandemic: Challenges, opportunities, and a call for submissions. Child and Adolescent Psychiatry and Mental Health. https://doi.org/10.1186/s1303 4-020-00324-8.

Publisher's Note Springer Nature remains neutral with regard to jurisdictional claims in published maps and institutional affiliations. 